Georgia State University

ScholarWorks @ Georgia State University

ExCEN Working Papers

Experimental Economics Center

4-20-2009

\title{
Procurement Auctions for Differentiated Goods
}

Jason Shachat

National University of Singapore

Todd Swarthout

Georgia State University

Follow this and additional works at: https://scholarworks.gsu.edu/excen_workingpapers

\section{Recommended Citation}

Shachat, Jason and Swarthout, Todd, "Procurement Auctions for Differentiated Goods" (2009). ExCEN Working Papers. 97.

https://scholarworks.gsu.edu/excen_workingpapers/97

This Article is brought to you for free and open access by the Experimental Economics Center at ScholarWorks @ Georgia State University. It has been accepted for inclusion in ExCEN Working Papers by an authorized administrator of ScholarWorks @ Georgia State University. For more information, please contact scholarworks@gsu.edu. 


\title{
Procurement Auctions for Differentiated Goods
}

\author{
Jason Shachat \\ National University of Singapore \\ J. Todd Swarthout \\ Georgia State University
}

This version: April 20, 2009

First version: January 28, 2003

\begin{abstract}
We consider two mechanisms to procure differentiated goods: a request for quote and an English auction with bidding credits. In the request for quote, each seller submits a price and the inherent quality of his good. Then the buyer selects the seller who offers the greatest difference in quality and price. In the English auction with bidding credits, the buyer assigns a bidding credit to each seller conditional upon the quality of the seller's good. Then the sellers compete in an English auction with the winner receiving the auction price and his bidding credit. Game theoretic models predict the request for quote is socially efficient but the English auction with bidding credits is not. The optimal bidding credit assignment under compensates for quality advantages, creating a market

distortion in which the buyer captures surplus at the expense of the seller's profit and social efficiency. In experiments, the request for quote is less efficient than the English auctions with bidding credits. Moreover, both the buyer and seller receive more surplus in the English auction with bidding credits.
\end{abstract}

Key Words: Procurement, Auction, Product Differentiation, Experiment JEL Classifications: C7, C9, L1 


\section{Introduction}

Large enterprises procure many goods for which the alternatives differ in quality. Often in such situations, the sellers find it neither feasible nor profitable to modify the non-price attributes of their goods. Some examples are the procurement of office furniture, hotel stays, and contract software programming. Traditionally, such goods are bought via a Request For Quote ( here after RFQ).

As part of their e-procurement agendas, many enterprises search for mechanisms that will provide better combinations of quality and price than does the RFQ. Most of these searches lead to an English auction. ${ }^{1}$ The promise to deliver the lowest cost seller through cutthroat price competition entices the enterprise. Unfortunately, when goods vary in quality, this aspect of an English auction can undermine the enterprise's efforts: often the lowest cost seller doesn't provide the best combination of price and quality. To address this issue, we introduce a stage prior to the English auction in which the buyer can assign bidding credits to sellers. Our primary concern is whether an enterprise's interest is better served by the English auction with bidding credits (henceforth EBC) or the RFQ.

Our research is part of the IBM procurement organization's evaluation of online auctions to procure differentiated goods. While the theory and experiments in this paper use abstract labeling for the economic environment, the focus of our activities is on the procurement of contract software programming. The numerical examples we provide and experimental parameter values we use are based upon this market. ${ }^{2}$ For this perspective the RFQ is the baseline for current practice while the EBC is an alternative we speculate is easy to implement, has good theoretical performance, and has a dominant strategy suppliers are likely to adopt.

A RFQ starts with the buyer providing her evaluation criteria for the non-price attributes, i.e. how she measures quality, to potential sellers. The buyer provides the evaluation criteria, even though the non-price attributes of a good are fixed. This way a seller knows the quality level assigned to his good. ${ }^{3}$ Next, each seller sets a price and provides the fixed description of his

\footnotetext{
${ }^{1}$ Within the e-procurement community the English auction is often called the Reverse auction.

${ }^{2}$ There are several website with auctions for contract programming services. Some examples are www.freelance.com and www.guru.com.

${ }^{3}$ Hence, we are not considering the buyer making a strategic choice of evaluation functions for RFQ's as in studies such as Dasgupta and Spulber (1990) and Che (1993). Furthermore, we don't address the issue of whether a buyer should reveal private information about this demand as in studies like Tan (1996) and Rezende(2009).
} 
product. The buyer, then, selects the seller who offers the largest margin between quality and price. The winning seller receives his submitted price.

In our formulation of the RFQ as a game of incomplete information, we define a seller's type as his realized surplus - quality minus cost - and a seller's bid as a surplus offer - quality minus price. Under this formulation, the RFQ is equivalent to a first price sealed bid auction for selling an object to potential buyers with independent private values. ${ }^{4}$ A seller's realized surplus in a RFQ is equivalent to a buyer's private value in a standard first price sealed bid auction; both are the potential gains from exchange that the auction participant provides. A surplus offer in a RFQ is equivalent to a buyer's bid in a first price sealed bid auction; both are an offer of utility by the bidder to the auctioneer. We exploit this equivalence to derive a symmetric Nash equilibrium for the RFQ. The symmetric equilibrium strategy is a surplus offer function that is an increasing function of realized surplus, ensuring the seller with the highest realized surplus wins and the auction is socially efficient. ${ }^{5}$

In an EBC, as in the RFQ, the buyer provides the evaluation criteria to the sellers, who in turn provide their product descriptions. Observing the quality of each good, the buyer assigns a bidding credit to the seller of each good. Then the sellers, each with bidding credit in hand, compete in an English auction. In the auction, sellers offer successively lower prices until the winning seller submits a price that no other seller is willing to improve upon. Again the winning seller receives the auction price and his bidding credit.

We derive the equilibrium strategies of the EBC by using a backward induction approach. For any bidding credit assignment, a seller's optimal strategy is to exit the auction when the price falls below his cost less his bidding credit. Anticipating the sellers following this strategy, the buyer's optimal bidding credit rule is discriminatory. In the case of two sellers, although the buyer assigns a larger credit to the seller of the higher quality good, the credit is smaller than his quality advantage. The buyer's optimal rule is reminiscent of the discriminatory policies of optimal auctions when sellers have asymmetric cost distributions. ${ }^{6}$ In these optimal auctions and

\footnotetext{
${ }^{4}$ First analyzed in a non-cooperative equilibrium framework by Vickrey (1961).

${ }^{5}$ This change of variable approach has been successfully and independently used in two recent papers on procurement with design tournaments: Fullerton et al. (2002) and Che and Gale (2002). In both of the papers, suppliers participate in a design contest to determine quality and then the enterprise uses and auction to purchase the innovation. Englebrecht-Wiggans, Haruvy, and Katok (2007) also use this approach for the same setting as ours.

${ }^{6}$ Myerson (1981), MacAfee and McMillan (1989), and Bulow and Roberts (1989) derive the optimal auctions for procurement when sellers have asymmetric costs.
} 
the EBC, the optimal discriminatory policies promote competitive pressure by subsidizing the disadvantaged seller and enrich the buyer at the expense of sellers' profits and social efficiency.

Our experimental results differ from the game theoretic predictions. In our experiments, the EBC is more socially efficient, providing a better average outcome to both the seller and buyer than the RFQ provides. In the RFQ experiments, many subjects' choices don't correspond to the Nash equilibrium strategy. The Nash equilibrium strategy of our RFQ is non-linear and other studies, such as Chen and Plott (1998), Georee and Offerman (2002), Pezanis-Christou (2002), and Guth et al. (2005), demonstrate that subjects tend not to play non-linear Nash equilibrium strategies.

Our EBC experiments are similar to the experiments of Cornes and Schotter (1999) that consider sealed bid procurement auctions that use price preferences to promote minority representation. Cornes and Schotter use fixed levels of the price preference as their treatment variable. They find the level of minority representation increases with the level of the price preference, but procurement costs are minimized at some interior level of the price preference. In our experiments we allow the buyer to choose the bidding credits. Buyers select discriminatory bidding credits, but not as discriminatory as advocated by the optimal bidding credit rule. The combination of the sellers' non-equilibrium behavior in the RFQ and the buyer's overly generous bidding credits in the EBC gives rise to the outcome of the EBC Pareto dominating the outcome of the RFQ.

Engelbrecht-Wiggans et al. (2007) is a theoretical and experimental study closely related to this one. They also consider procurement for differentiated goods with exogenous quality, and they compare the RFQ, which they call the buyer-determined auction, and a first price sealed bid price auction, which they call the price-determined auction. Their theoretical analysis shows that, under Nash equilibrium, with a small number of suppliers and little correlation between cost and quality, the price based auction provides more benefit to the procurement organization than the RFQ does. This is a result that applies to our setting and shows that even if a buyer assigns zero bidding credits in the English auction, he should do better than the RFQ. Empirically, Engelbrecht-Wiggans et al. develop an ingenious experiment in which quality and cost are positively correlated in such a way that equilibrium bid functions are linear. As a result, their RFQ auction is slightly more efficient than ours, but surprisingly not by much. In their first price sealed bid auction, they observe over aggressive and heterogeneous bidding that is typical in 
these types of auctions. In contrast to this in our EBC, suppliers bid very closely to the dominant strategy.

Haruvy and Katok (2008) adopt the Engelbrecht-Wiggans et al. setting to compare the performance of the RFQ versus a dynamic buyer determined English auction. This study is significant because the buyer determined English auction is the most common auction form used in online procurement auctions. The rather surprising result is that the RFQ soundly outperforms this auction in their experiments. This result, combined with the results presented in the current paper - namely the EBC generate a better outcome than the RFQ for both buyers and suppliers demonstrates strong potential for the EBC as a powerful procurement tool.

\section{Game Theoretic Models and Predictions}

In our analysis and experiments, we consider the case of two sellers and a buyer. Levels of cost and quality characterize a seller. Seller i's cost to produce a unit is a random variable, denoted $c_{i}$, which is uniformly distributed on the interval $\left[c_{L}, c_{H}\right]$. A seller incurs this cost only when he makes a sale. The quality of seller $i$ 's good is a random variable, denoted $v_{i}$, which is uniformly distributed on the interval $\left[v_{L}, v_{H}\right]$. You can think of this quality as the buyer's maximum willingness-to-pay for the good. The cost and the quality of each seller's good are independent random variables. We ensure that the quality of a seller's good always exceeds its cost by assuming $v_{L} \geq c_{H}$. At the time of the auction, each seller knows his quality and cost, but only the distributions of the quality and cost of the other seller's good. Also, the buyer knows the quality of each seller's good but only the distribution of his costs. This information structure is common knowledge.

Two of our assumptions merit additional comments. First, consider the assumption that both the buyer and supplier observe the quality of the supplier. In our study, quality differences between suppliers are the differences in the buyer's willingness-to-pay for each supplier's good. The dubious aspect of this assumption is that the supplier observes what is private information held by the buyer. Whether the supplier knows this information has no impact in the EBC, as a supplier's behavior does not depend upon his quality. This assumption does remove influential uncertainty from the RFQ, but this should lead to a more positive assessment of the RFQ than if this uncertainty was incorporated. The second assumption is the independence of a supplier's 
quality and cost. For the case of contract software programming, quality differences arise from idiosyncratic attributes such as the programmer's location, the timing of his availability, or the extent of his experience in a particular industry. It is likely in other applications of our results that quality and cost will be correlated. Our theoretical analysis is conceptually easy to extend to incorporate correlation, and we describe how this is done at the appropriate point. We do leave open the important question of how the correlation between quality and cost impacts behavior.

\section{II.1 Request For Quote Auction}

In this mechanism, potential sellers simultaneously submit prices. Seller $i$ 's submitted price is denoted $p_{i}$. Seller $i$ wins the auction if $v_{i-} p_{i}$ is the maximum of $\left\{v_{1}-p_{1}, v_{2}-p_{2}\right\}$ and receives the price $p_{i}$. In the case of a tie, a seller is selected at random from the set of winning suppliers. The winning seller i's profit is $p_{i^{-}} c_{i}$, the other seller's profit is zero, and the buyer's payoff is $v_{i^{-}} p_{i}$.

Although a seller $i$ 's type is the pair $\left(v_{i}, c_{i}\right)$, the relevant economic information is simply the difference of the two variables. The potential gains from exchange seller $i$ provides is $s_{i}=v_{i}{ }^{-} c_{i}$. We call $s_{i}$ seller $i$ 's “realized surplus." The random variable $s_{i}$ has a distribution function, denoted $F\left(\right.$ ), which is the convolution $v_{i}$ and $-c_{i}{ }^{7}$ Instead of explicitly considering the submitted price, we consider seller $i$ 's “surplus offer," $o_{i}=v_{i}-p_{i}$. Under this formulation, the seller who offers the buyer the largest surplus offer wins the RFQ auction.

With this change of variables, the RFQ has the same formulation as a first price sealed bid auction used to sell a single object to buyers with private values. In such a setting, each buyer's value is her realized surplus, or the potential gains from exchange she provides (assuming the seller has a cost of zero). When a participant makes a bid, she is making a surplus offer to the seller. And the highest bid is simply the greatest surplus offer. The equivalence of the RFQ, under the change of variables, and the first price sealed bid auction allows us to one to derive a symmetric Bayes-Nash equilibrium using standard arguments such as those found in McAfee and McMillan (1987).

The symmetric Bayes-Nash equilibrium surplus offer function for the RFQ is

\footnotetext{
${ }^{7}$ If quality and cost are correlated then we would derive the distribution of realized surplus by using the multivariate transformation theorem.
} 
$o_{i}^{*}=O\left(s_{i}\right)=s_{i}-\frac{\int_{V_{L}-C_{H}}^{s_{i}} F(z) d z}{F\left(s_{i}\right)}$.

This expression calculates how much of seller $i$ 's realized surplus he offers in equilibrium. From the equilibrium surplus offer function and the definition of realized surplus we get the equilibrium bid function

$$
p_{i} *\left(v_{i}, c_{i}\right)=c_{i}+\frac{\int_{V_{L}-C_{H}}^{s_{i}} F(z) d z}{F\left(s_{i}\right)} \text {. }
$$

This expression provides the margin demanded by the seller as a function of cost and quality.

For the $n$-seller case the equilibrium strategies are,

$$
o_{i}^{*}=O\left(s_{i}\right)=s_{i}-\frac{\int_{V_{L}-C_{H}}^{s_{i}}[F(z)]^{n-1} d z}{\left[F\left(s_{i}\right)\right]^{n-1}} \text { and } p_{i} *\left(v_{i}, c_{i}\right)=c_{i}+\frac{\int_{V_{L}-C_{H}}^{s_{i}}[F(z)]^{n-1} d z}{\left[F\left(s_{i}\right)\right]^{n-1}} \text {. }
$$

Consider the following example, which is based upon the parameters of our experiment. Let $\left[c_{L}, c_{H}\right]=[40,80]$ and $\left[v_{L}, v_{H}\right]=[100,130]$. Then the distribution of realized surplus, $s_{i}$, is

$$
F(s)= \begin{cases}\frac{(s-20)^{2}}{2400} & \text { for } 20 \leq s<50 \\ \frac{s-35}{40} & \text { for } 50 \leq s<60 \\ 1-\frac{(90-s)^{2}}{2400} & \text { for } 60 \leq s \leq 90\end{cases}
$$

The equilibrium surplus offer and bid functions resulting from this distribution are

$$
\begin{aligned}
& o *\left(s_{i}\right)=\left\{\begin{array}{l}
\frac{2 s_{i}+20}{3} \quad \text { for } 20 \leq \mathrm{s}<50 \\
s_{i}-\frac{300+\left(s_{i}-20\right)\left(s_{i}-50\right)}{2\left(s_{i}-35\right)} \quad \text { for } 50 \leq s<60 \text { and } \\
s_{i}-\frac{2400\left(s_{i}-55\right)+\frac{1}{3}\left(90-s_{i}\right)^{3}}{2400-\left(90-s_{i}\right)^{2}} \text { for } 60 \leq s \leq 90
\end{array}\right. \\
& p^{*}\left(v_{i}, c_{i}\right)=\left\{\begin{array}{l}
\frac{2 c_{i}+v_{i}+20}{3} \quad \text { for } 20 \leq \mathrm{s}<50 \\
c_{i}+\frac{300+\left(v_{i}-c_{i}-20\right)\left(v_{i}-c_{i}-50\right)}{2\left(v_{i}-c_{i}-35\right)} \quad \text { for } 50 \leq s<60 . \\
c_{i}+\frac{2400\left(v_{i}-c_{i}-55\right)+\frac{1}{3}\left(90-v_{i}+c_{i}\right)^{3}}{2400-\left(90-v_{i}+c_{i}\right)^{2}} \text { for } 60 \leq s \leq 90
\end{array} .\right.
\end{aligned}
$$


The equilibrium surplus offer and bid functions are depicted in Figure 1. After deriving a sequential Nash equilibrium of the EBC we will present some of the economic implications of this symmetric Nash equilibrium.

\section{II.2 English Auction with Bidding Credits}

We show that that the English Auction with bidding credits is an optimal auction; no other feasible non-cooperative mechanism provides a higher expected value for the procurement official. As above, we reformulate the situation as one in which suppliers have individual potential gains from exchange, and can offer surpluses to the buyer. In the more general sense the buyer, conditional upon his information, wants to design a mechanism that which selects a supplier and compensation that maximizes his expected benefit and at the same time is incentive compatible and feasible with the suppliers.

We once again exploit the change of variable that allows us to express the procurement problem into one where the supplier's types are potential gains from exchange. Since the buyer knows his maximum willingness-to-pay for each supplier $i$ 's unit, his belief about $s_{i}$ is $F\left(s_{i} \mid v_{i}\right)$. Myerson (1981) introduced the revelation principle: for any auction mechanism there is an equivalent direct revelation mechanism -- a game in which each $i$ ‘s action space is his set possible types and all players truthfully reporting is a Nash equilibrium -- which yields the same expected payoffs. Thus we can search for the optimal mechanism in the class of direct revelation games. Myerson shows that the optimal mechanism involves evaluating each revealed type, $\widetilde{s_{l}}$ according to the following rule

$$
r_{i}\left(\widetilde{s_{l}}\right)=\widetilde{s_{l}}-\frac{1-F\left(\widetilde{s_{l}} \mid v_{i}\right)}{f\left(\widetilde{s_{l}} \mid v_{i}\right)}
$$

There are two stages in this mechanism. In the first stage, the buyer assigns a bidding credit to each seller, conditioning it upon the seller's quality. Seller $i$ 's bidding credit is denoted $b_{i}$. In the second stage of the auction, each seller is told his respective bidding credit and then the sellers participate in an English auction. The winning seller receives a monetary amount equal to the auction price and his assigned bidding credit. 
We now derive a sequential Nash equilibrium for this mechanism. Each of a seller's information sets in stage two is defined by his bidding credit and the cost and quality of his good. A seller $i$ 's behavioral strategy is to set an exit price, $e_{i}$, for the English auction, i.e. the continuation game, at each of his information sets. Also we require that the seller update his belief about the other seller's type at each of his information sets via Baye's Rule. This is only a formality because each seller has a weakly dominant strategy.

Proposition 1: Seller $i$ has a weakly dominant strategy: $e_{i} *\left(b_{i}, c_{i}, v_{i}\right)=c_{i}-b_{i}$.

In other words seller $i$ remains in the auction as long as the standing price is greater than or equal to the seller's cost less his assigned bidding credit.

Proof: Apply one of the standard arguments, such as Krishna (2002) p.15, that establish the weakly dominant strategy in the second price sealed bid or English auctions. Just recalibrate the seller's zero payoff price to his cost less his bidding credit.

Now we derive the buyer's optimal bidding credit assignment in stage one. At this point, one could be tempted to simply appeal to the famous optimal mechanism literature result, Myerson (1982), which states for this example you give a bidding credit equal to half the quality advantage in conjunction with quality specific reserve price, and then show that the EBC implements this. Unfortunately, we can't make that appeal as we are requiring that procurement official makes a purchase. In the absence of reserve prices, this simple bidding credit is no longer optimal. So we must proceed to directly calculate to optimal bidding credit rule.

A buyer's payoff is the difference between the quality and the price paid (auction price plus bidding credit) of the procured object. The buyer's expected payoff ${ }^{8}$ for a pair of bidding credits - when sellers adopt their dominant strategies - is

$$
\begin{aligned}
E\left[\Pi\left(b_{1}, b_{2}\right)\right]= & \operatorname{Pr}\left[c_{1}-b_{1} \leq c_{2}-b_{2}\right]\left(v_{1}-E\left(c_{2}-b_{2} \mid c_{2}>c_{1}-b_{1}+b_{2}\right)-b_{1}\right) \\
& +\operatorname{Pr}\left[c_{1}-b_{1}>c_{2}-b_{2}\right]\left(v_{2}-E\left(c_{1}-b_{1} \mid c_{1}>c_{2}+b_{1}-b_{2}\right)-b_{2}\right)
\end{aligned} \text { or }
$$

\footnotetext{
${ }^{8}$ If quality and cost were correlated we would express the expectation of each cost term also to be conditional upon the corresponding quality.
} 


$$
\begin{aligned}
E\left[\Pi\left(b_{1}, b_{2}\right)\right]= & \operatorname{Pr}\left[c_{1}-b_{1} \leq c_{2}-b_{2}\right]\left(v_{1}-E\left(c_{2} \mid c_{2}>c_{1}-b_{1}+b_{2}\right)+b_{2}-b_{1}\right) \\
& +\operatorname{Pr}\left[c_{1}-b_{1}>c_{2}-b_{2}\right]\left(v_{2}-E\left(c_{1} \mid c_{1}>c_{2}+b_{1}-b_{2}\right)+b_{1}-b_{2}\right)
\end{aligned} .
$$

Inspection of this payoff function reveals that there are payoff equivalent strategy classes for the buyer: two pairs of bidding credits $\left(b_{1}, b_{2}\right)$ and $\left(b^{\prime}{ }_{1}, b^{\prime}{ }_{2}\right)$ yield the same expected payoff if $b_{1}-b_{2}$ $=b^{\prime}{ }_{1}-b^{\prime}{ }_{2}$. Let $K$ be the set of payoff equivalent strategies with the typical element $k$, where $k \in K=\left\{\left(b_{1}, b_{2}\right): b_{1}-b_{2}=k\right\}$. From this point, when we consider a particular $k$ we will be considering the unique bidding credit pair for which at least one of the suppliers receives a bidding credit of zero. With this notation, the buyer's expected payoff function is

$$
\begin{aligned}
E[\Pi(k)]= & \operatorname{Pr}\left[c_{1}-k \leq c_{2}\right]\left(v_{1}-E\left(c_{2} \mid c_{2}>c_{1}-k\right)-k\right) \\
& +\operatorname{Pr}\left[c_{1}-k>c_{2}\right]\left(v_{2}-E\left(c_{1} \mid c_{1}>c_{2}+k\right)+k\right) .
\end{aligned}
$$

The term $\operatorname{Pr}\left[c_{1}-k \leq c_{2}\right]$ is the probability that seller one wins the auction. This corresponds to the probability of the event $A=\left\{c_{1}-k \leq c_{2}\right\}$. The figure below show the two shapes this event can take in the support of $\left(c_{1}, c_{2}\right)$.

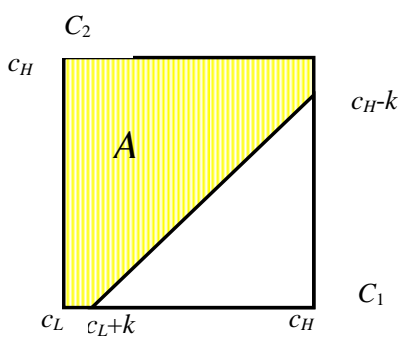

Case 1: $k>0$

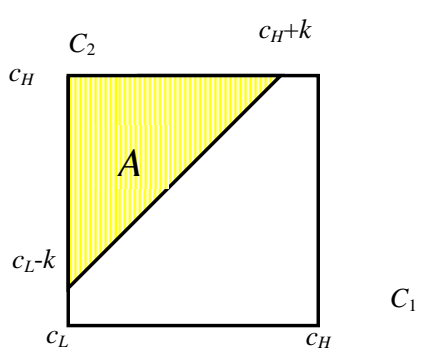

Case 2: $k<0$

With a rectangular distribution on the support, the probability that seller one wins the auction is

(2) $\operatorname{Pr}\left[c_{1}-k \leq c_{2}\right]=\left\{\begin{array}{c}\frac{2\left(c_{H}-c_{L}\right)^{2}-\left(c_{H}-c_{L}-k\right)^{2}}{2\left(c_{H}-c_{L}\right)^{2}}, \text { if } k \geq 0 \\ \frac{\left(c_{H}-c_{L}+k\right)^{2}}{2\left(c_{H}-c_{L}\right)^{2}}, \text { otherwise }\end{array}\right.$. 
Start with the case $k \geq 0$. When seller one wins the auction the expected auction price is $E\left(c_{2} \mid c_{2} \geq c_{1}-k, k \geq 0\right)$. To calculate this expectation we need the probability density function for the auction price. The cumulative distribution function for the auction price is

$$
\text { (3) } G(y) \equiv \operatorname{Pr}\left(\left\{c_{2} \leq y \mid c_{2} \geq c_{1}-k\right\}\right)=\frac{\operatorname{Pr}\left(\left\{c_{2} \leq y\right\} \cap\left\{c_{2} \geq c_{1}-k\right\}\right)}{\operatorname{Pr}\left(\left\{c_{2} \geq c_{1}-k\right\}\right)} \text {. }
$$

Recall $A=\left\{c_{1}-k \leq c_{2}\right\}$ and let $B=\left\{c_{2} \leq y\right\}$. The figure below shows the relevant events in the support of $\left(c_{1}, c_{2}\right)$ for the case where $k \geq 0$.

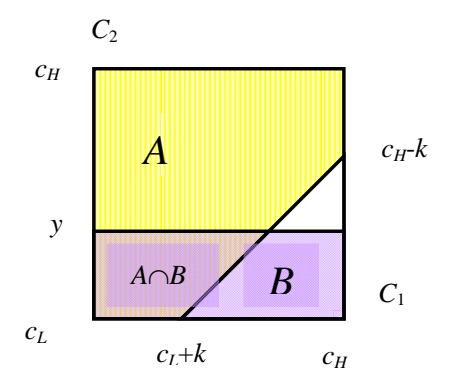

Direct calcula When $c_{L} \leq y \leq c_{H}-k$

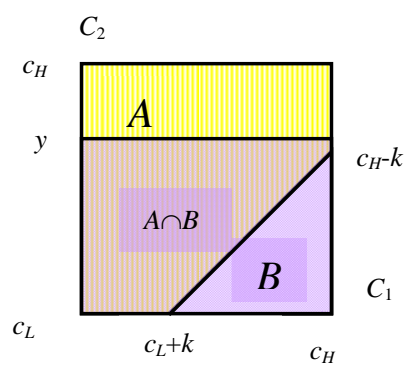

(4) $\operatorname{Pr}(A \cap B)=\left\{\begin{array}{c}\frac{\left(y-c_{L}\right)\left(2 k+y-c_{L}\right)}{2\left(c_{H}-c_{L}\right)^{2}}, \text { if } c_{L} \leq y \leq c_{H}-k \\ \frac{2\left(y-c_{L}\right)\left(c_{H}-c_{L}\right)-\left(c_{H}-c_{L}-k\right)^{2}}{2\left(c_{H}-c_{L}\right)^{2}}, \quad \text { if } c_{H}-k \leq y \leq c_{H}\end{array}\right.$.

Substitution of (2) and (4) into (3) gives us

$$
G(y)=\left\{\begin{array}{c}
\frac{\left(y-c_{L}\right)\left(2 k+y-c_{L}\right)}{2\left(c_{H}-c_{L}\right)^{2}-\left(c_{H}-c_{L}-k\right)^{2}}, \text { if } \quad c_{L} \leq y \leq c_{H}-k \\
\frac{2\left(y-c_{L}\right)\left(c_{H}-c_{L}\right)-\left(c_{H}-c_{L}-k\right)^{2}}{2\left(c_{H}-c_{L}\right)^{2}-\left(c_{H}-c_{L}-k\right)^{2}}, \quad \text { if } c_{H}-k \leq y \leq c_{H}
\end{array} .\right.
$$

Differentiate this expression to obtain the density function of $y$ :

$$
g(y)=\left\{\begin{array}{ll}
\frac{2\left(k+y-c_{L}\right)}{2\left(c_{H}-c_{L}\right)^{2}-\left(c_{H}-c_{L}-k\right)^{2}}, & \text { if } c_{L} \leq y \leq c_{H}-k \\
\frac{2\left(c_{H}-c_{L}\right)}{2\left(c_{H}-c_{L}\right)^{2}-\left(c_{H}-c_{L}-k\right)^{2}}, & \text { if } c_{H}-k \leq y \leq c_{H}
\end{array} .\right.
$$

The expected value of $c_{2}$ conditional upon $k$ and seller one winning the auction is 
$E(y)=\int_{c_{L}}^{c_{H}} y g(y) d y=\frac{\int_{c_{L}}^{c_{H}-k}\left(2 y^{2}+2 k y-2 c_{L} y\right) d y+\int_{c_{H}-k}^{c_{H}} 2\left(c_{H}-c_{L}\right) y d y}{2\left(c_{H}-c_{L}\right)^{2}-\left(c_{H}-c_{L}-k\right)^{2}}$ or

(5) $E(y)=\frac{2}{3} c_{H}+\frac{1}{3} c_{L}-\frac{k\left(c_{H}-c_{L}\right)^{2}+k^{2}\left(c_{H}-c_{L}-k\right)}{6\left(c_{H}-c_{L}\right)^{2}-3\left(c_{H}-c_{L}-k\right)^{2}}$.

The first term in this expression is the expectation of the first order statistic of the draw of two costs and the second term is the deviation from this expectation as $k$ changes.

For the parameters of our experiment,

$$
E(y) \equiv E\left(c_{2} \mid c_{2} \geq c_{1}-k, k \geq 0\right)=66 \frac{2}{3}-\frac{k}{3}\left(1-\frac{40 k}{1600+80 k-k^{2}}\right) .
$$

One consistency check on this expression is to set $k=0$, i.e. the special case of a simple English auction. When $k=0$, the expected value of the auction price conditional upon seller one winning is the expected value of the maximum cost statistic, $66 \frac{2}{3}$. A second consistency check is to set $k=40$ and guarantee that seller one wins the auction. Here the expected value of $y$ is 60 , the unconditional expectation of seller two's cost.

Now we calculate the expected price when seller two winning the auction, i.e.

$E\left(c_{1} \mid c_{1}-k \geq c_{2}, k \geq 0\right)$. In this instance,

$\operatorname{Pr}\left(\left\{c_{1}-k \geq c_{2}\right\}\right)=\frac{\left(c_{H}-c_{L}+k\right)^{2}}{2\left(c_{H}-c_{L}\right)^{2}}$ and

$\operatorname{Pr}\left(\left\{c_{1} \leq y\right\} \cap\left\{c_{1}-k \geq c_{2}\right\}\right)=\left\{\begin{array}{cl}0, & \text { if } y \leq c_{L}+k \\ \frac{\left(y-c_{L}-k\right)^{2}}{2\left(c_{H}-c_{L}\right)^{2}}, & \text { if } c_{l}+k \leq y \leq c_{H}\end{array}\right.$.

One can verify these probabilities from the following diagram.

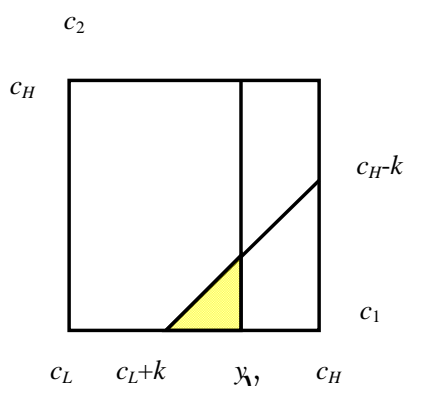

$c_{1} \leq y$ and $c_{1}-k \geq c_{2}$ 
The cumulative distribution function of the auction price when seller two wins is

$$
G(y)=\left\{\begin{array}{cl}
0, & \text { if } y \leq c_{L}+k \\
\frac{\left(y-c_{L}-k\right)^{2}}{\left(c_{H}-c_{L}-k\right)^{2}}, & \text { if } c_{l}+k \leq y \leq c_{H}
\end{array} .\right.
$$

This is the CDF of the maximum statistic for two independent draws from a uniform distribution on the interval $\left[c_{L}+k, c_{H}\right]$, permitting us to state:

(6) $E\left(c_{1} \mid c_{1}-k \geq c_{2}, k \geq 0\right)=\frac{2}{3} c_{H}+\frac{1}{3} c_{L}+\frac{1}{3} k$.

After substituting (2), (5), and (6) into (1) and simplifying, the buyer's expected payoff function for $k \geq 0$ is

$$
\begin{aligned}
E[\Pi(k \mid k \geq 0)]=\left[\frac{2\left(c_{H}-c_{L}\right)^{2}-\left(c_{H}-c_{L}+k\right)^{2}}{2\left(c_{H}-c_{L}\right)^{2}}\right]\left(v_{1}-\frac{2}{3} c_{H}-\frac{1}{3} c_{L}+\frac{k\left(c_{H}-c_{L}\right)^{2}+k^{2}\left(c_{H}-c_{L}-k\right)}{6\left(c_{H}-c_{L}\right)^{2}-3\left(c_{H}-c_{L}-k\right)^{2}}-k\right) \\
+\left[\frac{\left(c_{H}-c_{L}+k\right)^{2}}{2\left(c_{H}-c_{L}\right)^{2}}\right]\left(v_{2}-\frac{2}{3} c_{H}-\frac{1}{3} c_{L}+\frac{2}{3} k\right) .
\end{aligned}
$$

Let's consider the case where $k<0$. The symmetry of the probability and conditional expectation calculations allows us to immediately state the expected payoff in this case:

$$
\begin{aligned}
& E[\Pi(k \mid k<0)]=\left[\frac{\left(c_{H}-c_{L}+k\right)^{2}}{2\left(c_{H}-c_{L}\right)^{2}}\right]\left(v_{1}-\frac{2}{3} c_{H}-\frac{1}{3} c_{L}-\frac{2}{3} k\right) \\
& \quad+\left[\frac{2\left(c_{H}-c_{L}\right)^{2}-\left(c_{H}-c_{L}+k\right)^{2}}{2\left(c_{H}-c_{L}\right)^{2}}\right]\left(v_{2}-\frac{2}{3} c_{H}-\frac{1}{3} c_{L}+\frac{k\left(c_{H}-c_{L}\right)^{2}+k^{2}\left(c_{H}-c_{L}-k\right)}{6\left(c_{H}-c_{L}\right)^{2}-3\left(c_{H}-c_{L}-k\right)^{2}}+k\right) .
\end{aligned}
$$

Without loss of generality, assume seller one is the seller with the higher quality good. The following lemma indicates that is never in the buyer's interest to give a larger bidding credit to the lower quality seller, i.e. choose $k<0$.

Proposition 2: $E[\Pi(0)]>E[\Pi(k \mid k<0)]$.

\section{Proof:}

$$
\begin{aligned}
& E[\Pi(0)]-E[\Pi(k \mid k<0)]=\frac{1}{2}\left(v_{1}-v_{2}\right)-\frac{\left(c_{H}-c_{L}+k\right)^{2}}{2\left(c_{H}-c_{L}\right)^{2}} v_{1}-\left[1-\frac{\left(c_{H}-c_{L}+k\right)^{2}}{2\left(c_{H}-c_{L}\right)^{2}}\right] v_{2} \\
& +\frac{\left(c_{H}-c_{L}+k\right)^{2}}{2\left(c_{H}-c_{L}\right)^{2}} \frac{2 k}{3}-\left[1-\frac{\left(c_{H}-c_{L}+k\right)^{2}}{2\left(c_{H}-c_{L}\right)^{2}}\right] k-\left[1-\frac{\left(c_{H}-c_{L}+k\right)^{2}}{2\left(c_{H}-c_{L}\right)^{2}}\right] \frac{k\left(c_{H}-c_{L}\right)^{2}+k^{2}\left(c_{H}-c_{L}-k\right)}{6\left(c_{H}-c_{L}\right)^{2}-3\left(c_{H}-c_{L}-k\right)^{2}} .
\end{aligned}
$$


The term $\frac{1}{2}\left(v_{1}-v_{2}\right)-\frac{\left(c_{H}-c_{L}+k\right)^{2}}{2\left(c_{H}-c_{L}\right)^{2}} v_{1}-\left[1-\frac{\left(c_{H}-c_{L}+k\right)^{2}}{2\left(c_{H}-c_{L}\right)^{2}}\right] v_{2}$ is strictly positive because a negative $k$ reduces the probability of seller one winning below one-half. Also the term $\frac{\left(c_{H}-c_{L}+k\right)^{2}}{2\left(c_{H}-c_{L}\right)^{2}} \frac{2 k}{3}-\left[1-\frac{\left(c_{H}-c_{L}+k\right)^{2}}{2\left(c_{H}-c_{L}\right)^{2}}\right] k$ is strictly positive. Finally the term $-\left[1-\frac{\left(c_{H}-c_{L}+k\right)^{2}}{2\left(c_{H}-c_{L}\right)^{2}}\right] \frac{k\left(c_{H}-c_{L}\right)^{2}+k^{2}\left(c_{H}-c_{L}-k\right)}{6\left(c_{H}-c_{L}\right)^{2}-3\left(c_{H}-c_{L}-k\right)^{2}}$ is also strictly positive. Therefore, $E[\Pi(0)]-E[\Pi(k \mid k>0)]>0$. Q.E.D.

With this proposition, we examine the case of $k \geq 0$ for the optimal bidding credit assignment $k^{*}$. The first order condition for the maximization of the buyer's payoff is

$$
\frac{d E[\Pi(k *)]}{d k}=\frac{2 k^{* 2}-\left[3\left(c_{H}-c_{L}\right)+\left(v_{1}-v_{2}\right)\right] k *+\left(c_{H}-c_{L}\right)\left(v_{1}-v_{2}\right)}{4}=0 \text {. }
$$

The second order condition is

$$
\frac{d^{2} E\left[\Pi\left(k^{*}\right)\right]}{d k^{2}}=\frac{4 k^{*}-3\left(c_{H}-c_{L}\right)-\left(v_{1}-v_{2}\right)}{4} \leq 0 .
$$

The first order condition is a quadratic. Of the two roots, only the negative one satisfies the second order conditions for the maximum. The negative root and optimal bidding credit rule is $k^{*}=\frac{3\left(c_{H}-c_{L}\right)+\left(v_{1}-v_{2}\right)-\sqrt{\left[3\left(c_{H}-c_{L}\right)+\left(v_{1}-v_{2}\right)\right]^{2}-8\left(c_{H}-c_{L}\right)\left(v_{1}-v_{2}\right)}}{4}$.

Proposition 3: The optimal bidding credit assignment is less than the differences in quality, i.e. $k^{*}<v_{1}-v_{2}$.

Proof: $k^{*}<\left(v_{1}-v_{2}\right) \Rightarrow$

$$
\begin{aligned}
& 3\left(c_{H}-c_{L}\right)-3\left(v_{1}-v_{2}\right)-\sqrt{\left[3\left(c_{H}-c_{L}\right)+\left(v_{1}-v_{2}\right)\right]^{2}-8\left(c_{H}-c_{L}\right)\left(v_{1}-v_{2}\right)}<0 \Rightarrow \\
& 9\left(c_{H}-c_{L}\right)^{2}-18\left(c_{H}-c_{L}\right)\left(v_{1}-v_{2}\right)-9\left(v_{1}-v_{2}\right)^{2}<9\left(c_{H}-c_{L}\right)^{2}-2\left(c_{H}-c_{L}\right)\left(v_{1}-v_{2}\right)+\left(v_{1}-v_{2}\right)^{2} \Rightarrow \\
& -16\left(c_{H}-c_{L}\right)\left(v_{1}-v_{2}\right)-10\left(v_{1}-v_{2}\right)^{2}<0 \text {. Q.E.D. }
\end{aligned}
$$

According to proposition three, the buyer's best strategy in the EBC is to use a discriminatory rule that assigns a bidding credit to the high quality seller that is less than his quality advantage. 
The impact of the rule bolsters the low quality seller's competitiveness and leads the high quality seller to receive lower expected surplus than in the RFQ.

Again consider the environment of our experiment; two sellers who independently and uniformly draw costs from the interval $[40,80]$ and qualities from the interval $[100,130]$. After the buyer observes each seller's quality, has assigns to the higher quality seller the bidding credit

$$
k^{*}=\frac{\left(120+v_{1}-v_{2}\right)-\sqrt{\left(40+v_{1}-v_{2}\right)^{2}+12800}}{4} \text {. }
$$

An inefficient outcome occurs when the high quality seller's costs is in the interval $\left[c_{2}+k^{*}, c_{2}+\left(v_{1}-v_{2}\right)\right]$. For example, if $\left(v_{1}, c_{1}\right)=(120,60)$ and $\left(v_{2}, c_{2}\right)=(110,55)$ seller one has the greatest realized surplus but seller two wins the EBC. Specifically, the buyer assigns the optimal bidding credit of 1.58 to seller one, and seller two wins the auction at a price of 58.42.

\section{II.3 Economic Performance}

Using the Nash equilibrium strategies for the RFQ and EBC we can generate theoretical predictions of economic variables such as efficiency, market price, the average quality and cost of the procured good, and buyer's welfare. Table I presents the expected values of various economic variables for the economic environment of our experiment. Each of the following variables is associated with one the columns in Table II: “\% of Efficient Outcomes" or the percentage of auctions that select the seller with the greatest difference between quality and cost, "Avg. Realized Surplus” or the sum of the buyer's surplus and the winning seller's profit, "Avg. Winning Seller's Quality,” "Avg. Auction Price” (for the EBC this is the auction price and bidding credit paid), “Avg. Winning Seller’s Cost,” “Avg. Buyer’s Surplus” or the winning seller's quality less total price paid, and “Avg. Wining Seller's Profit.” We obtained all of the expected values, except “\% of Efficient Outcomes” for the RFQ, by simulating each auction ten million times.

The predicted outcomes of the two mechanisms differ for many variables. The RFQ always generates a socially efficient outcome because the symmetric Nash equilibrium strategy is strictly increasing in realized surplus. In contrast, the EBC selects the inefficient seller over 16 percent of the time. Also, the buyer's discriminatory bidding credit assignments reduce the average winning seller quality. Of course, the EBC more than makes up for this lower quality 
with a reduced price and a bias towards the lower cost seller. Also, the EBC leads to a gain in buyer welfare and a reduction in seller profit.

From a theoretical perspective, the EBC better serves the buyer's interest than the standard RFQ. But does human behavior conform to the models used to derive our predictions? Past experimental studies show that human choice often differs from game theoretic predictions and we will see this occur again in our experiments.

\section{Experimental Design}

All of our experimental sessions, except one, were conducted via a computer software application at the UCSD Department of Economics EEXCL facility. We conducted the other session at the IBM TJ Watson Research facility. Every session was a RFQ or EBC session.

Each subject received a show up fee of five US dollars prior to participating in a session (except for the IBM session at which a twenty dollar payment was given.) Before the decisionmaking portion of a session, each subject read a paper copy of the instructions and then had to successfully complete a simple written test of how the auction worked and how earnings were calculated. After the experiment each subject was privately paid his or her earning in US currency.

In a RFQ session, all subjects were designated as sellers. The subjects participated in five practice periods with no payments and then fifty additional periods with cash payments proportional to their experimental earnings. Prior to each period, subjects were randomly paired to participate in different auctions. At the start of each period, each subject was informed of his or her quality and cost. Then, each seller privately submitted a price, and a winner was determined. Subjects were informed of whether they won the auction, the winning auction price, and their period earnings. A complete history of this information was always available to a subject.

In an EBC session, two-thirds of the subjects were randomly designated sellers and one-third of the subjects were randomly assigned to the buyer roll. After two practice periods, subjects participated in twelve to sixteen periods in which cash earnings accumulated. ${ }^{9}$ Before each

\footnotetext{
${ }^{9}$ An EBC auction lasted significantly longer than a RFQ auction, and consequently we used and 20 experimental dollar to one US dollar exchange rate in EBC sessions and a four to one exchange rate in the RFQ sessions.
} 
period, a collection of trios was formed by randomly matching two sellers and one buyer. Each trio participated in their own auction. At the beginning of an auction, the buyer was informed of the quality of each seller's good, and each seller was informed of the quality and unit cost of his or her good. Then the buyer had the opportunity to assign a credit to each of the sellers. Once these credits were assigned, they were revealed to the respective sellers.

Next, an iterative English auction commenced with sellers making opening offers. In subsequent iterations, the seller who didn't have the lowest current offer could either exit the auction or make an offer lower than the current lowest offer. The seller with the current lowest offer could either maintain his current offer or improve it. When one of the sellers exited, the auction concluded. The current lowest price at the conclusion set the auction price.

The winning seller received the auction price and his assigned credit less his unit cost. The buyer received the difference between the quality of winning seller's good and the total payment to the winning seller. The losing seller received zero earnings. Over the course of the session, subjects could see a complete history of the information that had been revealed to them. We conducted four RFQ sessions with forty-four total subjects; two with 12 subjects each and two ten subjects each. Each RFQ session was completed in less than ninety minutes. We conducted four EBC sessions: The number of participants and periods in each session is given in the following table. All EBC sessions were completed in 105 minutes.

\begin{tabular}{ccccc}
\hline $\begin{array}{c}\text { EBC } \\
\text { Session }\end{array}$ & $\begin{array}{c}\text { Total } \\
\text { Periods }\end{array}$ & $\begin{array}{c}\text { Practice } \\
\text { Periods }\end{array}$ & Sellers & Buyers \\
\hline 1 & 14 & 2 & 10 & 5 \\
2 & 18 & 2 & 6 & 3 \\
3 & 16 & 2 & 10 & 5 \\
4 & 16 & 2 & 8 & 4 \\
\hline
\end{tabular}

\section{Results on Empirical Economic Performance}

Under Nash equilibrium play, the RFQ is socially efficient, while the EBC better serves the buyer's interest at the expense of efficiency and seller profit. Contrary to these predictions, in experiments, the EBC is more efficient and nominally makes both buyer and seller better off than 
the RFQ. The difference between the comparative theoretical and empirical economic performances mostly results from play that diverges from the theory in the RFQ experiments.

In Table II, we provide statistics for various performance variables in the RFQ and EBC auctions. For both the RFQ and EBC sessions, we provide the sample mean and standard deviation for each variable. Also, for each variable, we provide the $z$-statistic and its p-value for the hypothesis test that the means are the same both auction types. A bold-faced p-value indicates the hypothesis is rejected at a five percent level-of-significance.

The EBC, not the RFQ, provides a more socially optimal outcome in the experiments. In over 84 percent of the EBC auctions, the higher surplus seller wins and the average total realized social surplus is 63.25 , while the higher surplus seller wins only 79 percent of RFQ auctions and the average total realized social surplus is 61.53. Dividing realized social surplus into its two components, we see that the average buyer surplus is about 1.7 percent greater and the average seller profit is about 5.2 percent greater in the EBC than in the RFQ. ${ }^{10}$

How buyers and sellers in the EBC benefit from the advantage in average social surplus is found by examining the average realized qualities, prices, and costs. The RFQ auction generates a higher quality level than the EBC, 117.69 versus 116.26 , but also an increase in costs, 56.15 versus 53.01. The net effect of these two differences is the 1.71 advantage in total social surplus enjoyed by the EBC. Also, the average EBC price is 2.52 lower than the RFQ price. From the seller's perspective, the net effect of the price and cost reductions is a .62 increase in profit in the EBC. From the buyer's perspective, the reduction in quality is more than offset by the reduction in cost, and result in a 1.09 increase in buyer surplus in the EBC.

The differences between the relative empirical performances and the game theoretic predictions must mean at least one of the auctions is performing differently than its Nash equilibrium predictions. Table III presents the observed and theoretical values of the reported performance variables, and hypothesis tests that the observed and theoretical values are the same. The theoretical predictions of the RFQ are rejected at the 5 percent level of significance for all variables except Avg. Winning Seller's Quality. On the other hand, for the EBC, the theoretical prediction is only rejected for a single variable. The observed buyer surplus is significantly less than predicted. Clearly the Nash Equilibrium predictions fare worse for the RFQ than the EBC.

\footnotetext{
${ }^{10}$ However, the improvement in surplus for the buyer and seller in the EBC is not significant according to the z-test.
} 
Subjects not using Nash equilibrium strategies must be the source of the theoretical prediction's failures.

\section{Analysis of Individual Behavior}

To understand how the equilibrium predictions fail we must identify how subjects' behavior is deviating from the equilibrium strategies. First, we consider subject behavior in the RFQ experiments. Here we show that sellers offer too much surplus when they receive high-realized surplus types and too little surplus when they receive low surplus types. Also subjects offer different surpluses to the buyer for distinct quality-costs pairs that provide the same realized surplus. Regression analysis shows that there are two distinct types of bidders: those who make nonlinear bids that are correlated with the Nash bids, and those who submit bids linear in cost and quality. This mixture model explains the why sellers are too "generous" or too "stingy" depending upon their realized surplus types. In the EBC, we see that buyers are too generous with their bidding credit assignments and that sellers follow their dominant strategy with one caveat; the losing seller on average exits the auction about three dollars before their zero profit price. This bias takes away some of the buyer's surplus in the EBC.

\section{V.1 Behavior in the RFQ}

To what extent do subjects' surplus offers correspond to the Nash Equilibrium surplus offer function? When we plot surplus offers versus realized surplus as in Figure II we don't find evidence that subjects follow the Nash surplus offer function. We do see at low levels of realized surplus subjects will offer less than Nash levels of surplus, while at middle levels of realized surplus the surplus offers exceed the Nash Levels, and at high levels of realized surplus there is tremendous variation in the level of surplus offers. The scatter plot of Surplus Offers also has several linear bands. Each of the bands represents a focal amount of profit demanded by a seller such as ten, twenty, or thirty dollars. These bands could be indicative of subjects who only ask for a fixed absolute margin independent of their quality. The presence of these bands and the large variation in the surplus offers raises a question; is a subject's surplus offer determined by the difference in quality and cost or more generally by the absolute values of quality and costs? 
Defining realized surplus as a seller's type is key to solving for the symmetric Nash equilibrium strategy, but assuming a subject's behavior is solely characterized by his realized surplus, or the difference in quality and cost, may be inappropriate. To understand how subjects condition their choices on the absolute levels of cost and quality we consider the difference between submitted and Nash bids for different quality-cost pairs. In Figure III, we present the average difference between submitted and Nash bids for different ranges of cost-quality pairs. We start by defining 100 equal sized bins that cover the supports of the cost and quality variables. For each bin we select all the instances when a subject drew a cost-quality pair in the range of the bin. For each of these instances, we calculate the deviation of the submitted bid from the Nash bid. We calculate the average of all the deviations in the bin, and the average is the reported as the height of the bar of the bin in Figure III.

The graphs of these averages reveal systematic patterns. First, for each level of cost the difference between the submitted and Nash bid falls as quality increases. Evidently, subjects don't fully appreciate the competitive advantage associated with higher quality levels. Second, when costs are high and quality is low - i.e., a low level of realized surplus - submitted bids are greater than Nash bids. This is counter to the Nash equilibrium feature that the lowest type demands zero profit. Third, for low cost-high quality bins the bids are below the Nash levels. Finally, if the subjects condition their behavior only on the level of realized surplus, then we would expect the average bid deviation to be the same for a constant level of realized surplus. Bins corresponding to the same level realized surplus lie on off-diagonal lines of the cost-quality range. Inspection of the bar graphs does not suggest equal bid biases for bins lying on these offdiagonals. Hence, subjects' behavior is not invariant to the absolute levels of cost and quality.

Given the significant variation observed when we pool subject behavior, we now ask whether subjects decisions are noisy or whether their is systematic heterogeneity in the subjects' bidding rules. We proceed by allowing for two possibilities; a subject's bids could either be a linear function of cost and quality or correlated with the non-linear Nash bid function. A linear bid for subject $i$ function has the following form:

$$
p_{i}\left(c_{i}, v_{i}\right)=\beta_{0}+\beta_{1} c_{i}+\beta_{2} v_{i},
$$

where the betas are unknown coefficients. We formulate the nonlinear Nash bid model as

$$
p_{i}\left(c_{i}, v_{i}\right)=\gamma_{0}+\gamma_{1} p^{*}\left(c_{i}, v_{i}\right),
$$


where $p^{*}()$ is the Nash bid function. If a bidder exactly follows the Nash bidding rule, then $\gamma_{0}=$ 0 and $\gamma_{1}=1$. The two models allow us to characterize linear bidders and bidders who follow non-linear rules that are close to the Nash equilibrium strategy. We want to ascertain, for each subject, whether either of these models is appropriate.

We use the J-test of Davidson and MacKinnon (1981) to determine the selection from the two non-nested models. First we imbed the two models into one specification

$$
p_{i}\left(c_{i}, v_{i}\right)=(1-\alpha)\left[\beta_{0}+\beta_{1} c_{i}+\beta_{2} v_{i}\right]+\alpha\left[\gamma_{0}+\gamma_{1} p^{*}\left(c_{i}, v_{i}\right)\right] .
$$

We use OLS to estimate this model. Then we run two hypothesis tests: $\alpha=0$ and $\alpha=1$. There are four possible outcomes to this exercise. First, we could reject both hypotheses and we select the larger nesting model. Second, we could not reject both hypotheses. This would indicate that both models are adequate and that the models are highly co-linear. Third, we could reject $\alpha=0$ but not $\alpha=1$. In this case we select Nash model. Finally we could reject $\alpha=1$, but not $\alpha=0$. In this case we select the linear bid model. Recall the Nash bid function is linear over part of the cost-quality range and in this range the two models can correspond. This can confound the identification of which bidding function a subject follows. Nevertheless, our results allow us to make a definitive model assignment for half of the subjects.

We apply the J-test to each subject's data in the RFQ and find substantial heterogeneity in the bidding strategies. In Table III, we report for each subject the model selected, the estimated parameters of the selected model, and the r-square statistic. For twenty-two of the forty-four subjects we are able to select a single model. Six subjects follow the Nash bidding model and sixteen follow the linear bidding model. The $J$-test selects both models for ten subjects. For these subjects we report the coefficient estimates for the model with the cost, quality and Nash bid parameters. Inspection of the regression results reveals some classic signs of multicollinearity: a high r-square, insignificant coefficients, and coefficients with the wrong sign. For these ten subjects the two models are too similar to differentiate. For the remaining twelve subjects, we reject both the linear and Nash model in favor of the nested model. Here we report the regression results for the nested regression and again observe the signs of multicollinearity.

The $J$-test exercise demonstrates there are large contingencies of both non-linear Nash bidders and linear bidders. The presence of linear bidders leads to inefficient auction outcomes; linear bidding rules leads to low prices for high quality goods. Consequently, the Buyer's surplus is significantly higher and the Seller's profit is significantly lower than under the Nash equilibrium. 


\section{V.2 Behavior in the EBC}

Subject behavior in the EBC is adheres closer to the game theoretic predictions than it does in the RFQ. Again, a seller has a weakly dominant strategy in the auction: exit only when the price falls below cost minus bidding credit. Subjects do follow this prescription with a caveat. The losing seller exits the auction, on average, three dollars above his threshold price. The buyer's Nash strategy is not as apparent as the seller's. Most of the time the Buyers do assign non-zero bidding credits, but their assignments are on average too generous. The combination of sellers exiting the auction slightly early and the buyer's assigning overly generous bidding credits leads to greater efficiency and seller profit than predicted.

How closely do sellers adhere to the dominant strategy? In Figure IV, we provide a histogram of the difference between the losing seller's exit price and his dominant strategy exit price. Most losing sellers exit slightly above their zero profit prices. Specifically, over 81 percent of the deviations are between zero and four - the average price and auction close at was close to sixtyfour. In contrast, only 2.4 percent of the losing sellers exit after the zero profit price and only three out of 248 auction winners lose money. Sellers clearly understand the dominant strategy and exit close to, but not below, their zero profit prices. We conjecture that the tediousness of the English auction is responsible for the early exit behavior. ${ }^{11}$

The Buyers’ bidding credit assignments greatly vary and on average are more generous than the optimal bidding credits. First, approximately twenty-five percent of the time the buyer does not utilize the bidding credits to give an advantage to the high quality seller. Specifically, in over eighteen percent of the auctions the buyer assigns the same bidding credit to both sellers, and in almost seven percent of the auctions the buyer assigns a larger bidding credit to the lower quality. In these cases the buyer is certainly not using the bidding credits to manage quality differences. At the other end of the spectrum, in almost six percent of the auctions the difference in the assigned bidding credits is equal to the difference in quality. Here, while the buyer is ensuring the best seller is selected, he is not capturing any additional surplus over the Nash equilibrium outcome of the RFQ. In Figure V, we provide a scatter plot of the difference in

\footnotetext{
${ }^{11}$ This raises a potential issue with the Nash equilibrium analysis; if the subjects were actually discounting their auction payoffs, then our open outcry implementation of the auction allows alternative equilibrium involving jump bidding as discussed in Isaac, Salmon, and Zillante (2002).
} 
bidding credit versus the difference in quality, a graph of the optimal bidding credit rule, and a graph of the OLS trend line. The trend line is above the optimal assignment line, but the OLS trend also has a low r-square that reflects highly variable Buyer behavior. Although the EBC has a transparent dominant strategy for sellers, the optimal bidding assignment rule proves elusive to the buyers. However, as seen in Figure V, the majority of the time the buyers do use discriminatory assignments.

The experimental results provide an assessment of the impact the choice of auction has on the effectiveness of procurement activities. The empirical performance of the RFQ leaves opportunities for other mechanisms to improve upon the status quo. As our experiments show, the EBC produces greater total surplus and/or better serves the buyer's interest depending upon the buyer's objective and rule for assigning bidding credits.

\section{Concluding Remarks}

In this paper, we assess two alternative ways enterprises can procure differentiated goods. The first alternative is the traditional method of request for quote. We show that under a symmetric Nash equilibrium the RFQ is an efficient mechanism. The second alternative is an English auction in which the buyer can assign bidding credits to the sellers based upon the qualities of the goods offered. This mechanism has a Nash equilibrium in which a seller has a transparent weakly dominant strategy, and the buyer has an optimal bidding credit assignment, which under compensates the high quality supplier for his quality advantage. This discriminatory policy improves the buyer's welfare over what she receives in the RFQ at the expense of social efficiency and seller profit. However, in our experiments, we find the EBC outperforms the RFQ for both buyers and sellers because (1) sellers don't follow the symmetric Nash strategy in the RFQ and because (2) buyers assign overly generous bidding credits in the EBC.

The transformation of how enterprises procure goods and services is one promise the emergence of e-commerce has actually fulfilled. Part of this transformation is an increase in the use of English auction variations. In practice, these English auctions for procurement of differentiated goods are not equivalent to the English auctions typically studied by economists. Specifically an English auction does not determine the supplier; the auction only sets each participating seller's price. After the auction, the buyer selects the winning seller and pays that 
seller his exit price from the auction. This is how implementations of English procurement auctions manage product differentiation — Kinney (2000).

The EBC is a potentially attractive alternative to current procurement English auction practices. In the current business use of English auctions, a seller no longer has a transparent dominant strategy and, more importantly, a buyer can't credibly commit to a discriminatory policy when they select a seller after the auction. Evaluating the non-price attributes of goods after the auction, the buyer is less likely to use a discriminatory policy. This would require sometimes selecting a seller who does not provide the best combination of price and quality. In the EBC, the evaluation of quality prior to auction is an opportunity to pre-commit to a discriminatory policy, which doesn't suffer from the credibility problem of exercising the policy after the auction.

Another promising application of the EBC and its strategic transparency to the supplier is its use to manage the longer term procurer supplier relationship. As noted by Jap (2007), current applications of the Reverse auction alienate this relationship and can lead to worse procurement performance. This study demonstrates that smart use of the EBC can lead to making both the suppliers and buyer better off. This comes from the fact in the various forms of procurement auctions without transparent dominant strategies, bidders fail to adopt Nash equilibrium bidding strategies and lead to inefficient market outcomes. EBC can allow one to recover these lost gains from exchange.

\section{References}

Bulow, Jeremy and John Roberts, “The Simple Economics of Optimal Auctions,” Journal of Political Economy, 97, 1060-1090 (1989).

Che,Yeon-Koo, "Design competition through multidimensional auctions," Rand Journal of Economics, 24, 668-680 (1993).

Che,Yeon-Koo and Ian Gale, "Optimal design of research contracts,” American Economic Review, (forthcoming).

Chen, Kay-Yut and Charles R. Plott, "Nonlinear behavior in sealed bid first price auctions," Games and Economic Behavior, 25, 34-78 (1998).

Corns, Allan and Andrew Schotter, "Can affirmative action be cost effective? An experimental examination of price preference auctions," American Economic Review, 89, 291-305 (1999). 
Dasgupta, S. and D. F. Spulber, “Managing procurement auctions,” Information Economics and Policy, 4, 5-29 (1990).

Davidson, Russell and James G. MacKinnon, "Several tests for model specification in the presence of alternative hypotheses,” Econometrica, 49, 781-793 (1981).

Engelbrecht-Wiggans, Richard, Ernan Haruvy, and Elena Katok, “A comparison of buyerdetermined and price-based multi-attribute mechanisms,” Marketing Science, 26, 629-641 (2007).

Fullerton, Richard L. et al, "Using auctions to reward tournament winners: theory and experimental investigations,” RAND Journal of Economics, 33, 62-84 (2002).

Georee, Jacob K. and Theo Offereman, "Efficiency in auctions with private and common values: an experimental study,” American Economic Review, 92, 625-643 (2002).

Guth, Werner, Radosveta Ivanova-Stenzel, and Elmar Wolfstetterr, "Bidding behavior in asymmetric auctions: An experimental study,” European Economic Review, (7), pages 18911913 (2005).

Haruvy, Ernan and Elena Katok, “An Experimental Investigation of Buyer Determined Procurement Auctions” Unpublished Manuscript, Pennsylvania State University (2008).

Isaac, Mark Tim Salmon, and Arthur Zillante, "A theory of jump bidding in ascending auctions," Journal of Economic Behavior \& Organization, 62, 144-164 (2007).

Jap, Sandy D. "The impact of online reverse auction design on buyer-supplier relationships." Journal of Marketing, 71, 146-159 (2007).

Kinney, Sam, "RIP fixed pricing: the Internet is on its way to 'marketizing' everything," Business Economics, 35, 39-44 (2000).

Krishna, Vijay, Auction Theory, Academic Press, San Diego (2002).

McAfee, R. Preston and John McMillan, “Auctions and bidding,” Journal of Economics Literature, 25, 699-738 (1987).

McAfee, R. Preston and John McMillan, “Government procurement and international trade,” Journal of International Economics, 26, 291-308 (1989).

Myerson, Roger B., “Optimal auction design,” Mathematics of Operation Research, 6, 59-73 (1981). 
Pezanis-Christou, Paul, "On the impact of low-balling: Experimental results in asymmetric auctions," International Journal of Game Theory, 31, 69-89 (2002).

Rezende, Leonardo, “Biased procurement auctions,” Economic Theory, 38, 169-185 2009.

Tan, Guofu, “Optimal Procurement Mechanisms for an Informed Buyer,” Canadian Journal of Economics, 29, 699-716 (1996).

Vickery, William, “Counterspeculation, auctions, and competitive sealed tender,” The Journal of Finance, 16, 8-37 (1961). 


\section{Table I: Nash Equilibrium Predictions for the RFQ and EBC}

\begin{tabular}{|c|c|c|c|c|c|c|c|}
\hline Auction & $\begin{array}{c}\% \text { of } \\
\text { Efficient } \\
\text { Outcomes } \\
\end{array}$ & $\begin{array}{c}\text { Avg. } \\
\text { Winning } \\
\text { Seller Quality }\end{array}$ & $\begin{array}{l}\text { Avg. Auction } \\
\text { Price }\end{array}$ & $\begin{array}{c}\text { Avg. } \\
\text { Winning } \\
\text { Seller Cost }\end{array}$ & $\begin{array}{c}\text { Avg. Buyer } \\
\text { Surplus }\end{array}$ & $\begin{array}{l}\text { Avg. Winning } \\
\text { Seller Profit }\end{array}$ & $\begin{array}{l}\text { Avg. Realized } \\
\text { Social Surplus }\end{array}$ \\
\hline RFQ & $100 \%$ & 117.90 & 71.17 & 54.65 & 46.74 & 16.52 & 63.26 \\
\hline $\mathrm{EBC}$ & $83.41 \%$ & 115.55 & 66.79 & 53.37 & 48.76 & 13.41 & 62.17 \\
\hline
\end{tabular}




\section{Table II. Empirical Auction Performance: RFQ versus EBC}

$\%$ of Efficient Avg. Realized Avg. Winning Avg. Auction Avg. Winning Avg. Buyer Avg. Winning

\begin{tabular}{cccccccc} 
Auction & Outcomes & Social Surplus Seller Quality & Price & Seller Cost & Surplus & Seller Profit \\
\hline \hline RFQ & $79 \%$ & 61.53 & 117.69 & 68.37 & 56.16 & 49.32 & 12.21 \\
Stand. Dev. & 0.407 & 12.67 & 8.18 & 9.39 & 10.64 & 9.86 & 8.33 \\
\hline EBC & $84.27 \%$ & 63.25 & 116.26 & 65.85 & 53.01 & 50.41 & 12.83 \\
Stand. Dev. & 0.64 & 3.56 & 2.86 & 3.06 & 3.26 & 3.14 & 2.89 \\
\hline$\mu_{R F Q}-\mu_{E B C}$ & $-5.27 \%$ & -1.71 & 1.43 & 2.52 & 3.14 & -1.09 & -0.62 \\
$z$-stat & -2.01 & -2.00 & 2.37 & 3.45 & 4.74 & -1.25 & -0.94 \\
$F(z)$ & $\mathbf{0 . 0 2 2}$ & $\mathbf{0 . 0 2 3}$ & $\mathbf{0 . 9 9 1}$ & $\mathbf{1 . 0 0 0}$ & $\mathbf{1 . 0 0 0}$ & 0.106 & 0.173
\end{tabular}




\section{Table III: Auction Performance: Theoretic Predictions and Empirical Measurements}

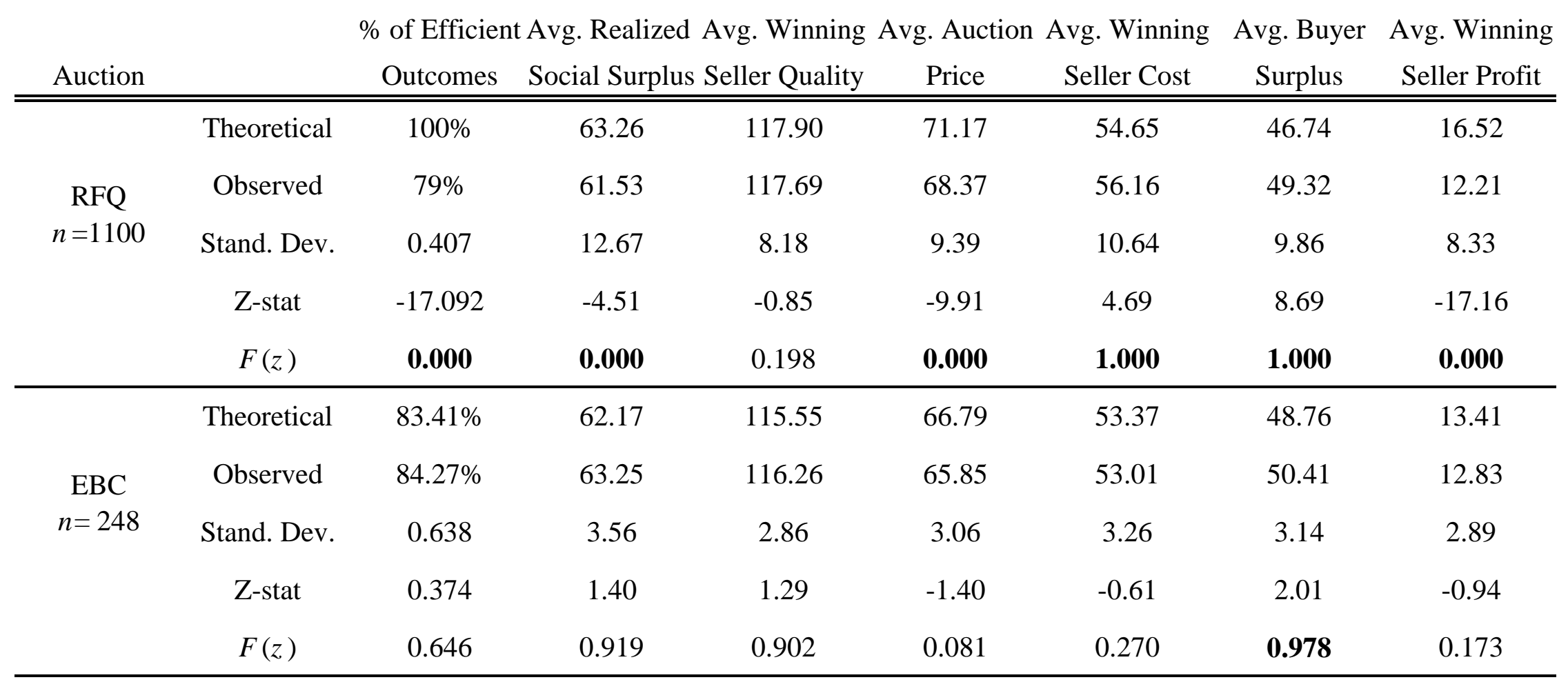




\section{Tabel IV: Estimated Bidding Models with $J$-test Selection Criteria For each Subject}

(Bold face indicates $t$-test does reject coefficient is zero; 50 observations for each subject)

\begin{tabular}{|c|c|c|c|c|c|c|}
\hline Subject & Intercept & Cost & Quality & NE Price & R-Square & Model Selected \\
\hline 1 & -4.10 & - & - & 1.04 & 0.85 & Nash Price \\
\hline 2 & -8.11 & - & - & 1.08 & 0.64 & Nash Price \\
\hline 3 & 14.10 & - & - & 0.78 & 0.62 & Nash Price \\
\hline 4 & 9.10 & - & - & 0.91 & 0.54 & Nash Price \\
\hline 5 & 13.80 & - & - & 0.79 & 0.54 & Nash Price \\
\hline 6 & 24.19 & - & - & 0.66 & 0.53 & Nash Price \\
\hline 7 & 5.29 & 0.74 & 0.15 & - & 0.94 & Linear Cost and Bid \\
\hline 8 & -1.69 & 0.92 & 0.12 & - & 0.93 & Linear Cost and Bid \\
\hline 9 & -2.25 & 0.68 & 0.27 & - & 0.88 & Linear Cost and Bid \\
\hline 10 & 0.05 & 0.89 & 0.10 & - & 0.85 & Linear Cost and Bid \\
\hline 11 & 10.20 & 0.66 & 0.19 & - & 0.82 & Linear Cost and Bid \\
\hline 12 & 8.28 & 0.68 & 0.21 & - & 0.81 & Linear Cost and Bid \\
\hline 13 & 9.54 & 0.76 & 0.11 & - & 0.81 & Linear Cost and Bid \\
\hline 14 & 12.44 & 0.81 & 0.08 & - & 0.77 & Linear Cost and Bid \\
\hline 15 & 2.20 & 0.65 & 0.26 & - & 0.75 & Linear Cost and Bid \\
\hline 16 & 12.88 & 0.86 & 0.02 & - & 0.67 & Linear Cost and Bid \\
\hline 17 & 13.82 & 0.61 & 0.22 & - & 0.65 & Linear Cost and Bid \\
\hline 18 & 10.80 & 0.63 & 0.18 & - & 0.64 & Linear Cost and Bid \\
\hline 19 & 6.93 & 0.61 & 0.23 & - & 0.62 & Linear Cost and Bid \\
\hline 20 & 18.35 & 0.91 & 0.05 & - & 0.55 & Linear Cost and Bid \\
\hline 21 & 18.45 & 0.67 & 0.14 & - & 0.47 & Linear Cost and Bid \\
\hline 22 & 38.65 & 0.59 & 0.05 & - & 0.33 & Linear Cost and Bid \\
\hline 23 & -4.05 & 0.40 & -0.06 & 0.75 & 0.93 & Both Models Selected \\
\hline 24 & 4.43 & -0.01 & -0.15 & 1.12 & 0.87 & Both Models Selected \\
\hline 25 & 12.30 & -1.20 & -0.71 & 2.89 & 0.86 & Both Models Selected \\
\hline 26 & -5.12 & -0.63 & -0.26 & 2.03 & 0.85 & Both Models Selected \\
\hline 27 & 1.68 & 0.20 & -0.07 & 0.88 & 0.84 & Both Models Selected \\
\hline 28 & 3.19 & -1.48 & -0.60 & 3.15 & 0.83 & Both Models Selected \\
\hline 29 & 35.84 & -0.45 & -0.66 & 1.86 & 0.83 & Both Models Selected \\
\hline 30 & 12.41 & -0.89 & -0.36 & 2.12 & 0.70 & Both Models Selected \\
\hline 31 & 40.41 & -0.31 & -0.45 & 1.39 & 0.60 & Both Models Selected \\
\hline 32 & 57.49 & -0.75 & -0.60 & 1.76 & 0.53 & Both Models Selected \\
\hline 33 & -11.02 & 0.08 & 0.01 & 1.00 & 0.82 & Neither Model Selected \\
\hline 34 & 15.39 & 0.33 & 0.01 & 0.54 & 0.79 & Neither Model Selected \\
\hline 35 & -3.13 & 0.41 & 0.49 & 0.06 & 0.71 & Neither Model Selected \\
\hline 36 & -2.15 & 0.30 & -0.02 & 0.77 & 0.70 & Neither Model Selected \\
\hline 37 & -7.04 & 0.19 & 0.30 & 0.53 & 0.67 & Neither Model Selected \\
\hline 38 & 24.90 & -0.78 & -0.49 & 2.14 & 0.58 & Neither Model Selected \\
\hline 39 & 8.10 & -0.17 & -0.02 & 1.04 & 0.57 & Neither Model Selected \\
\hline 40 & 36.39 & 0.23 & 0.06 & 0.25 & 0.41 & Neither Model Selected \\
\hline 41 & 19.83 & -0.71 & -0.36 & 1.95 & 0.33 & Neither Model Selected \\
\hline 42 & 43.29 & 0.16 & 0.03 & 0.33 & 0.26 & Neither Model Selected \\
\hline 43 & 37.00 & 0.43 & -0.05 & 0.31 & 0.21 & Neither Model Selected \\
\hline 44 & 27.52 & 0.64 & 0.48 & -0.63 & 0.12 & Neither Model Selected \\
\hline
\end{tabular}




\section{Figure 1: Graphs of RFQ Nash Equilibrium Strategies}

Graph of Equilibrium Offered Surplus Function $O *\left(s_{i}\right)$

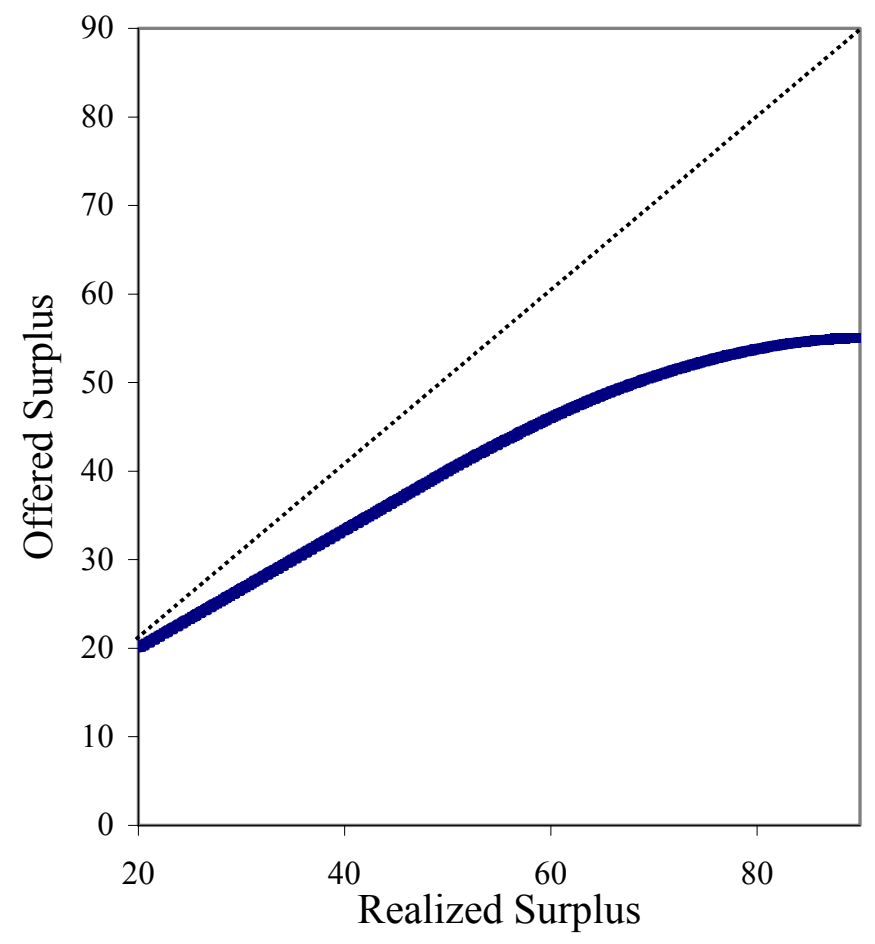

Level Curves of Equilibrium Bid Function $p *\left(v_{i}, c_{i}\right)$

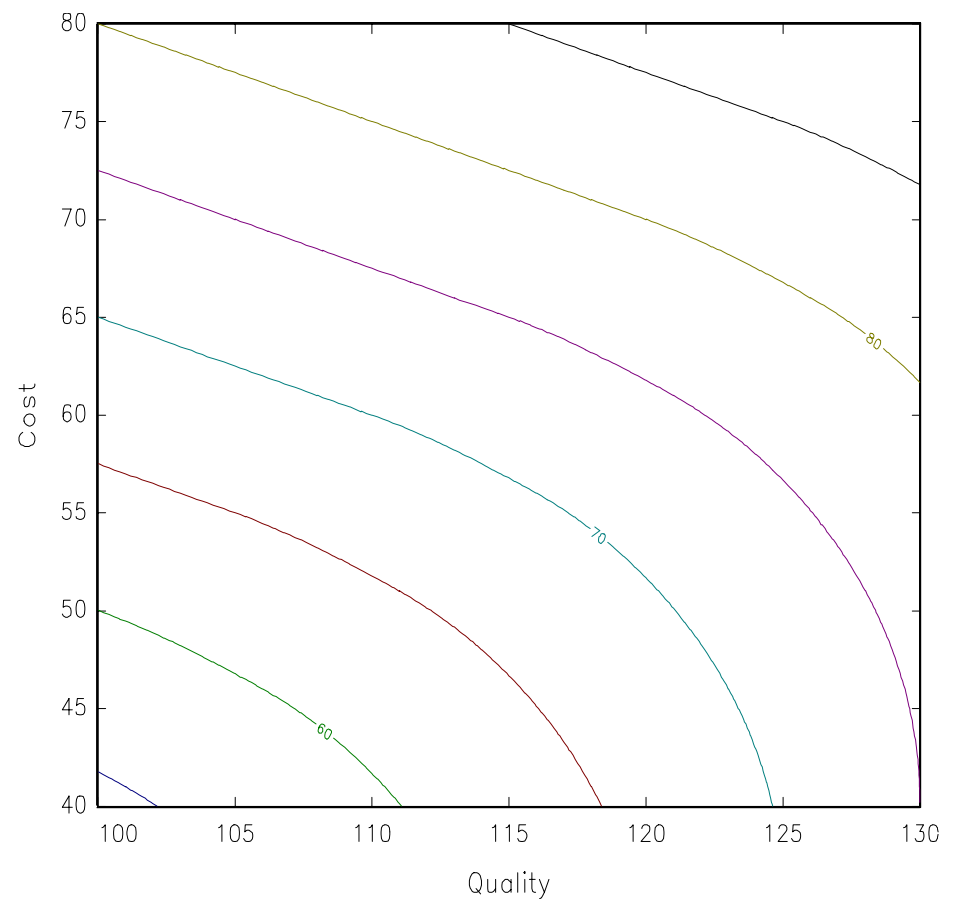




\section{Figure II: Surplus Offered}

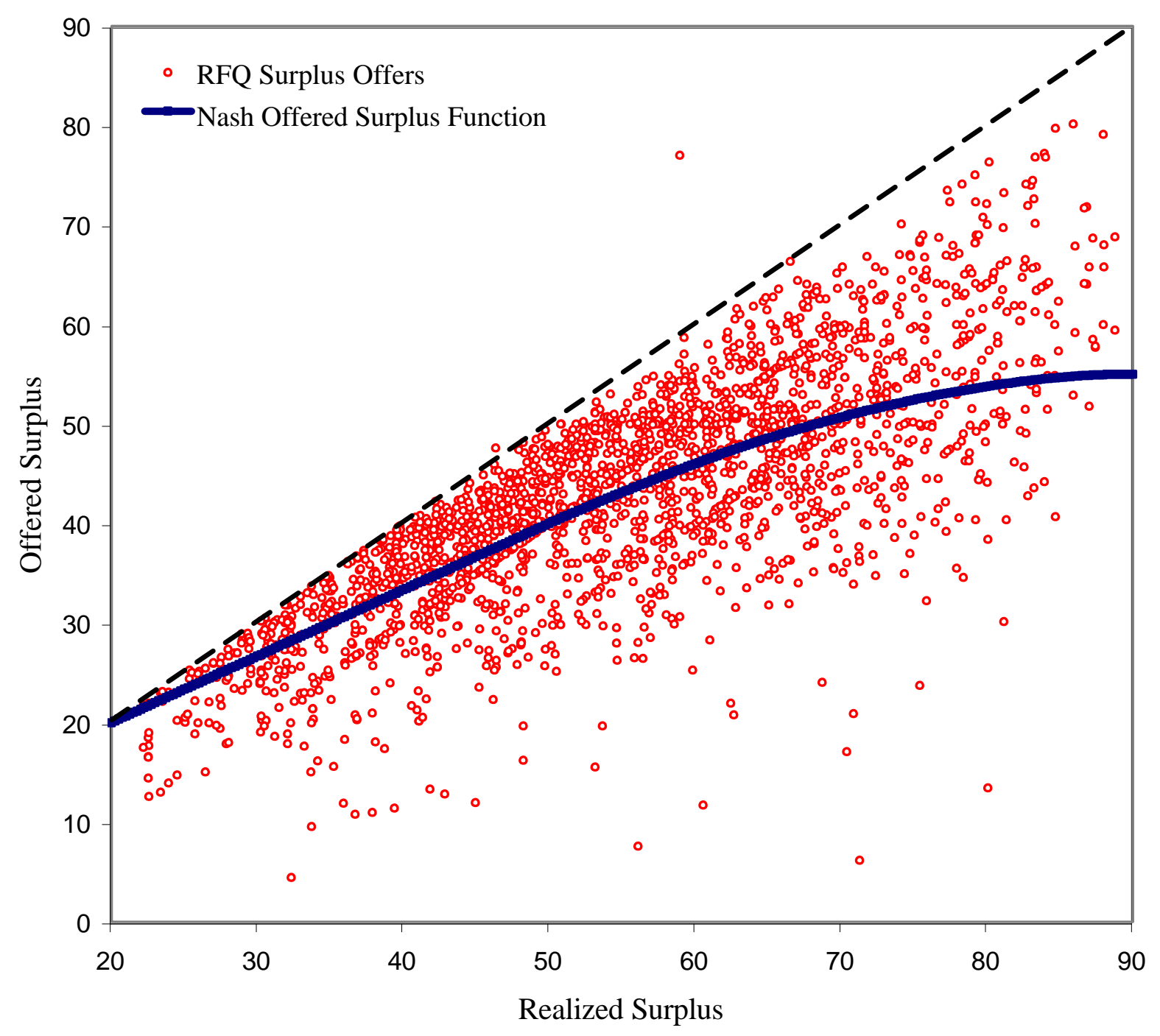


Figure III: The Average Difference Between the Actual Bid and the Predicted Bid for Different Cost-Quality Types

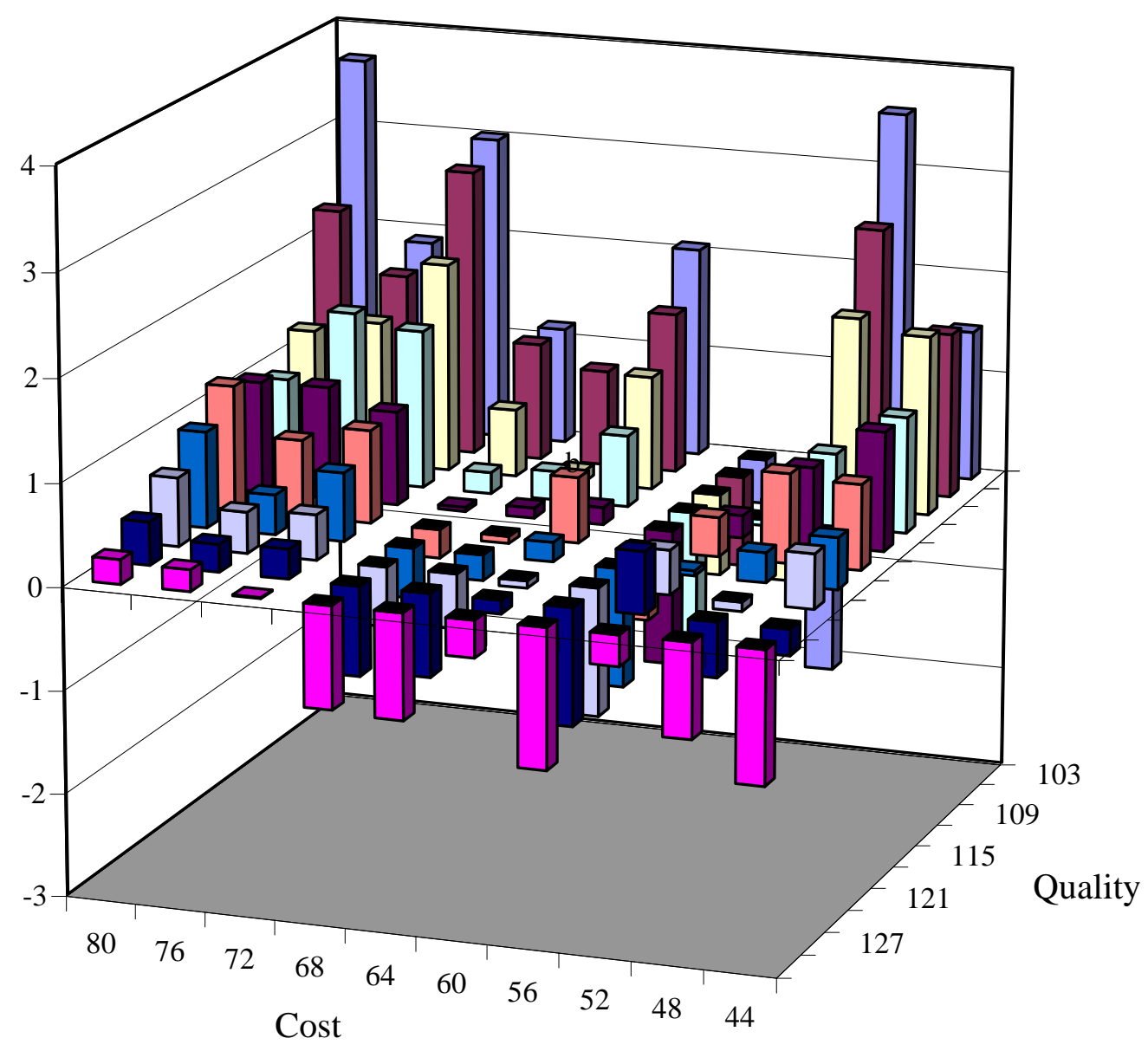


Figure IV: Devation of Losing Seller's Exit Price From

Dominant Strategy Exit Price

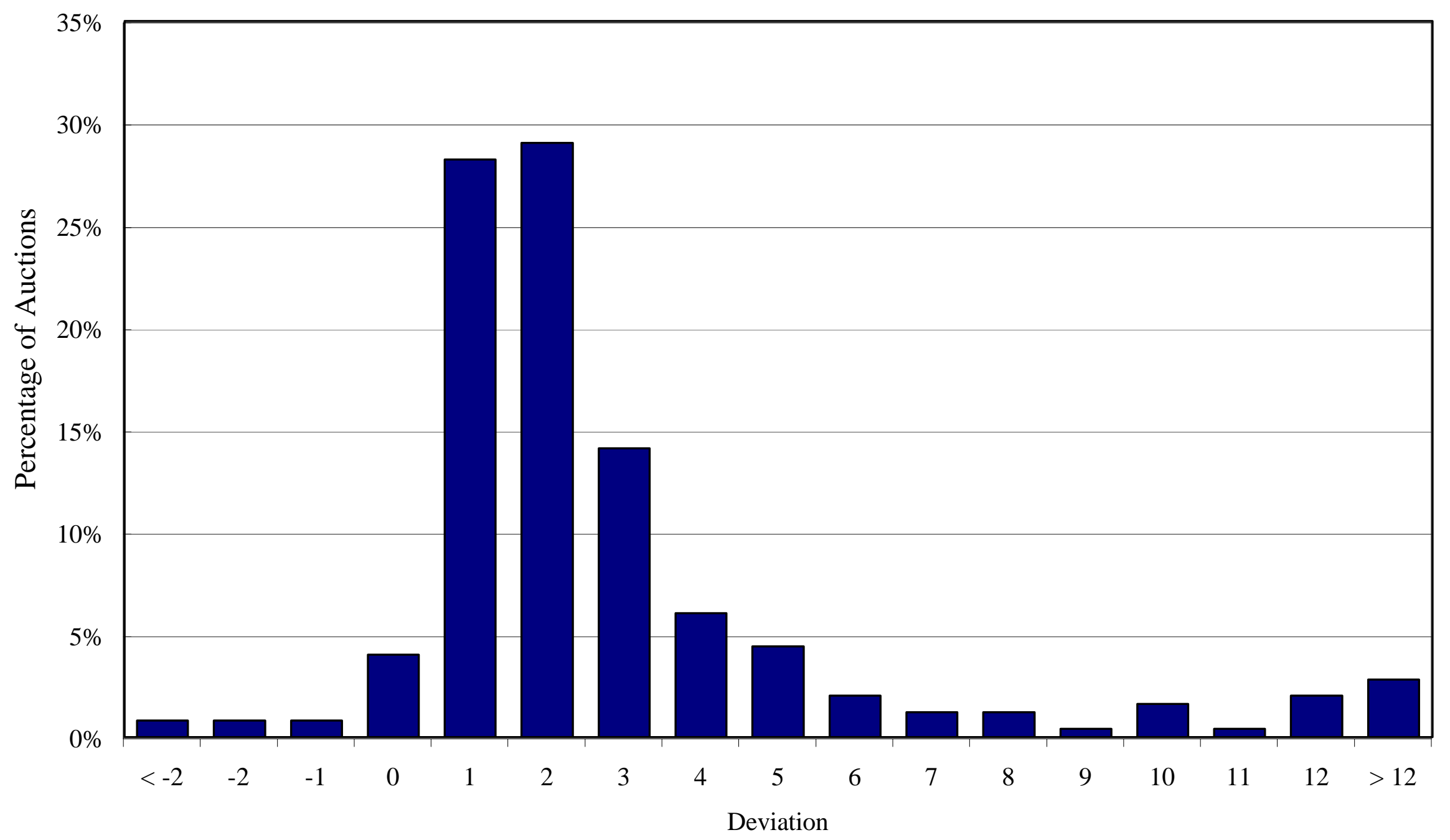


Figure V: Differences in Assigned Bidding Credits versus Differences in Quality

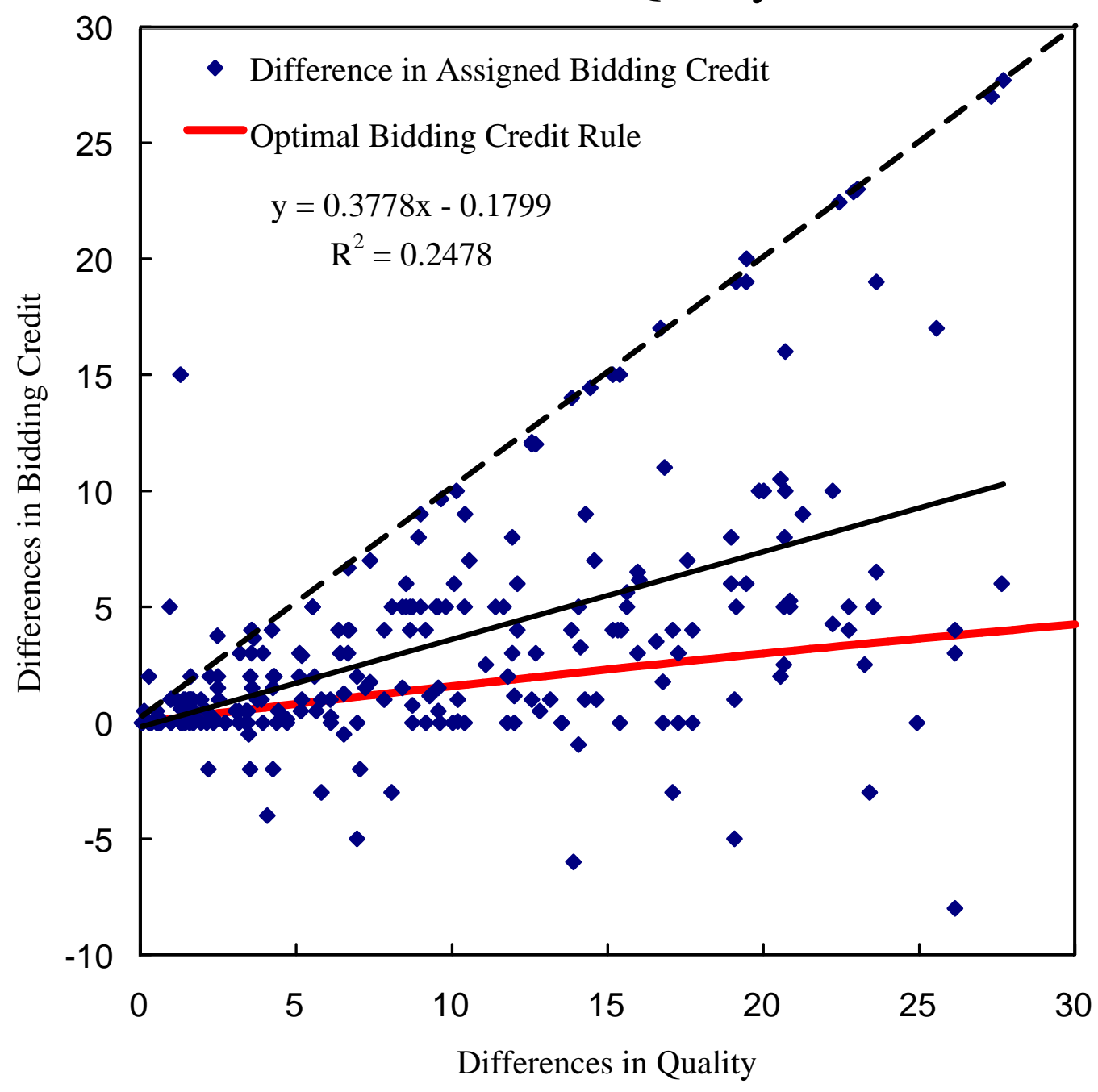

